INTERNATIONAL JOURNAL OF

MULTIDISCIPLINARY STUDIES ON MANAGEMENT,

BUSINESS, AND ECONOMY

VOLUME 2, ISSUE 2, 2019, $16-19$.

www.egyptfuture.org/ojs/

\title{
SUSTAINABLE DEVELOPMENT IN THE LIGHT OF QUALITY STANDARDS OF DESIGN AND THEIR RELATION TO PRODUCTION MANAGEMENT AND ELEMENTS OF PRODUCTION PROCESSES IN INTERIOR DESIGN
}

\author{
Sameh Mohamed Salem *
}

Architecture and Interior Decoration Department, Higher Institute of Applied Arts, Sixth of October, Cairo, Egypt

\begin{abstract}
The design in general is the first nucleus of any applied product, so the beginnings of the applied product must be by presenting the design in the correct manner to achieve the required quality, and with also relying on the beneficiary's evaluation to see the extent to which the quality of the products 'performance has improved, which can play a pivotal role as one Sustainable development strategies for any society. Therefore, correct planning to achieve the development and improvement of design specifications with their various treatments in the interior design is related to a great extent to raising the rates of efficiency of production processes, through the methods and means of properly managing production, taking into account the quality and simplicity of the design and avoiding additional costs, which greatly contributes to overcoming the problems of poor quality. There is great importance to activate the role of production departments and production processes to contribute to the advancement of societies by achieving leaps in the rates of economic growth for these societies through high-performance applied products that are consistent with the tastes and desires of the beneficiaries, while also achieving the financial and moral returns for individuals and institutions responsible for achieving the quality and effectiveness of design. Through the correct production management of the design product production stages and through its various production processes.

Keywords

SUSTAINABLE DEVELOPMENT - QUALITY STANDARDS- DESIGN - PRODUCTION MANAGEMENTELEMENTS OF PRODUCTION- PRODUCTION PROCESSES-INTERIOR DESIGN
\end{abstract}

\section{Introduction}

The design in general is the first nucleus of any applied product, so the beginnings of the applied product must be by presenting the design in the correct manner to achieve the required quality, and with also relying on the beneficiary's evaluation to see the extent to which the quality of the products 'performance has improved, which can play a pivotal role as one Sustainable development strategies for any society.

Therefore, correct planning to achieve the development and improvement of design specifications with their various treatments in the interior design is related to a great extent to raising the rates of efficiency of production processes, through the methods and means of properly managing production, taking into account the quality and simplicity of the design and avoiding additional costs, which greatly contributes to overcoming the problems of poor quality.

There is great importance to activate the role of production departments and production processes to contribute to the advancement of societies by achieving leaps in the rates of economic growth for these societies through high-performance applied products that are consistent with the tastes and desires of the beneficiaries, while also achieving the financial and moral returns for individuals and institutions responsible for achieving the quality and effectiveness of design. Through the correct production management of the design product production stages and through its various production processes.

Correctly managing the stages of production processes is one of the elements and foundations of managing the design quality system in the internal design to achieve the comprehensive quality system for the applied product that the market needs.

Therefore, careful examination and application of design quality standards for interior design processes and treatments in its various stages within the general engineering context of the project as a whole and linking all of this to the production management elements and production processes of the furniture and furnishing elements of the interior design of the project as a whole can provide us with a high-performance, applied

* Corresponding author: Info@AppliedArts.edu.eg 


\section{SUSTAINABLE DEVELOPMENT IN THE LIGHT OF QUALITY STANDARDS OF DESIGN AND \\ THEIR RELATION TO PRODUCTION MANAGEMENT AND ELEMENTS OF PRODUCTION PROCESSES IN INTERIOR DESIGN}

product that effectively contributes to achieving Sustainable development for any modern society. Sustainable development: It is the process of developing the land, cities and societies, provided that it meets the needs of the present, provided that the ability of future generations to meet their needs is not compromised.

Design Quality: is the translation of customer need and expectations about a product for specific characteristics that form the basis of product design.

The modern state: it is the state whose structure and system are characterized by the features of this era, coexist with the present and benefit from its data.

Productive processes: it is a group of activities that interact together that transform a product from one form to another.

The importance of the research: The research discusses one of the very important issues for the quality of design and production processes through the correct application of design quality standards, and its impact on production management and production processes for furniture and furnishing elements in interior design.

\section{Research problem:}

1- Lack of interest in applying the correct quality standards in the various design stages and passing through controlling the inputs of the internal design elements to control the outputs of production processes in interior design.

2- The absence of an actual mechanism that clarifies the relationship between the design quality standards in the interior design and between

Management of production and production process in interior design.

Research Objective:

1- The research aims to take advantage of design quality standards in interior design and apply them to production management and production processes for the elements of furnishing and interior design as one of the pillars through which one of the sustainable development strategies can be achieved for any modern society.

2- It is to shed light and clarify how to benefit from the quality standards of design in interior design and its reflection on the processes of producing furnishing elements in interior design.

Research Methodology:

The researcher follows the descriptive and analytical approach to describe, analyze and verify the facts and information obtained through the selected samples and samples.

\section{- $\quad$ Research hypotheses:}

1- The application of correct standards for design quality can improve the performance of production departments and the efficiency of production processes in the internal design of any society, which will be reflected later on its impact on achieving leaps in the rates of economic growth for any civilized society.

2- A good understanding of the mechanisms of quality design in the specialization of interior design can improve the quality of production processes, furnishing elements in interior design.

The definition of the concept of quality in the field of design and engineering sector

The concepts and definitions mentioned regarding the concept of quality have varied by experts and specialists in the fields of design and engineering sectors in general, the most important of which can be presented by specialists as follows:

\section{1- The American Society of Quality Control defined the following:}

It is the sum total of the features and characteristics that the design or product possesses, which are able to meet the stated and implicit needs, as well as the quality according to the definition of the European Organization for Quality Control: it is the performance of the work or the presentation of the design to the beneficiary correctly from the first time with reliance on the assessment of the beneficiary to know the extent improve the performance.

2- While Crosby believes that the definition of quality:

It is the accuracy of the appropriateness of the applied product to the design set forth, considering that the measure of the success of the applied product lies in the accuracy of implementing the designed design and its accuracy in conformity with that design. "While Edward defined quality in the field of designs and engineering sectors: it is the design treatments and engineering drawings that must be performed and approved. Throughout the years, through engineering inspection and examination of selected materials and materials to verify that the work matches the specified design and engineering requirements.

(Edward) has adopted an overall definition of the quality of designs and engineering drawings through design treatments and various engineering and construction processes as operations that include the following:

A- Setting specialized qualitative standards for design and engineering performances through plans and specifications.

B- Finding design and engineering deviations and comparing them with specifications.

$\mathrm{T}$ - take corrective actions for design and engineering deviations. 
D- Correct planning to develop and improve the specifications of the engineering and construction drawings and designs themselves.

Quality in stages of design furniture design processors procedure:

Since the first stage of the design process, thinking must be made to enhance the quality elements in product design, which are the elements of production processes in interior and engineering design one of them.

The design quality in the design of procedure:

The Design Quality Management specifications have defined the procedures and criteria for controlling designs, including the British standards (750 BSS5) as well as (7000 BS), and ISO specifications in its various versions and the Egyptian specifications for quality control through the Egyptian Organization for Standardization and Quality. Which belongs to the Ministry of Planning and others. These specifications stipulated that the following procedures be taken to control the design, namely:

Proper planning of the design.

- Adjusting the outputs that will emerge from this design through the applied products.

Verify production management mechanisms by implementing the stages of production processes for the various design stages.

- To prove the correctness of the implemented production processes - To control the changes that may occur during the various stages of implementation.

By following the steps to achieve the primary goal of evaluating the quality work in the interior design and engineering sectors and the aforementioned standards, which have been adopted, they are the organizational structure, design preparation teams, design planning, direction and communication, and the use of computer technologies designs and in the implementation stages of its various processes, and with testing and measuring The extent of the feasibility of designs to obtain from them to obtain a high-performance application product, and with the control of design documents and files.

production management and production processes and the internal design:

The general concept of production management and production processes is that activity that undertakes the process of standardizing design and production systems and then transforming them through the available resources for specific production systems to obtain an applied product. Through the application of design quality standards, a high-performance applied product can be obtained, and also through innovative design solutions. And applying design quality standards and continuous development of applied products, we can support and increase competitiveness to reach the applied product from local to global as one of the pillars of sustainable development of societies.

Mechanisms design quality and their relationship with the product applied to the productive processes:

The design in general and the interior design in particular is a creative activity that depends on the stated needs and the existing knowledge to bring it to a product that meets these stated needs and can be achieved.

The design of the products or the appropriate interior furnishing elements inside any space is in accordance with the stated or implicit requirements, which is the important stage for the quality of this product or the quality of this design as a service through which the benefit is achieved, and this stage results in the necessary steps to qualify the product or design treatment, so that the quality of these steps is considered Mainly for product quality or design processing quality, which supports this product and makes it competitive in the market.

Quality: is the correct performance of design elements and components to provide products that suit the needs and desires of the consumer. Quality is also known as: the ability to provide products (such as the design product) with characteristics that match the needs, desires and expectations of customers.

The high-quality design product contributes to supporting and increasing competition in the market for similar products, and this design product also helps improve the reputation of companies and design and production institutions from which the design came out, and it achieves complete satisfaction for customers and consumers, as it is also related to the efficiency of the stages of production processes implemented for it By achieving a streamlined flow of raw materials and production materials, which naturally leads to a reduction in wasted time through the movement of workers and raw materials, so that this contributes to achieving a lower production cost in operating and production processes.

Results :

1- There is a weakness in applying the quality standards of designs and not adopting modern methods and techniques in designing internal design projects, in addition to not adopting the correct methods in controlling the quality, arrangement and organization of production processes within the production institutions. 


\section{SUSTAINABLE DEVELOPMENT IN THE LIGHT OF QUALITY STANDARDS OF DESIGN AND THEIR RELATION TO PRODUCTION MANAGEMENT AND ELEMENTS OF PRODUCTION PROCESSES IN INTERIOR DESIGN}

2- Achieving design quality through good planning of the design stages and with controlling the inputs of the internal design elements within any engineering system leads to achieving control over the outputs of the design product as an applied product in the interior design, taking into account the review of the design, its treatments and the development of its technological tools to achieve the highest levels of quality.

3- Careful examination and application of design quality standards for interior design processes and treatments in its various stages within the general engineering context of the project as a whole and linking all of this to the production management elements and production processes of the furniture and furnishing elements of the interior design of the project as a whole can provide us with a high-performance applied product, which will contribute with His colleagues from projects in achieving leaps in the rates of economic growth of society, which is one of the central roles of sustainable development strategies for societies.

4- The accuracy and simplicity of design, which relates to its suitability at the end of the stages of its production processes as a high-performance applied product that the market needs, is one of the important elements and pillars within the departments of the design quality system, production elements and production processes to achieve the concept of the overall quality of the product.

5- Taking into account the continuous improvement in the quality of the work of the design and production departments and linking them to the stages of production processes in the design and production institutions to keep pace with the latest technologies in the field and specialization of interior design is one of the important criteria for investigating the quality of designs, as well as emphasizing the role of applied science in achieving sustainable development by providing solutions Innovative and creating investment opportunities.

\section{Recommendations:}

1- The necessity to define specific standards for the quality of designs in companies and interior design institutions with the need to focus on requiring companies and factories to implement furnishing elements for interior design through production departments and the elements of production processes on the obligation to provide a comprehensive implementation plan for the stages of production processes, and a quality plan for the design as a whole within the conditions of application The concept of the total quality of the applied product, which is one of the most important factors for achieving sustainable development in light of design quality standards.

2- The necessity of acquainting the engineering cadres and interior design designers with the main modern programs and techniques in the engineering fields while training them on how to deal with the problems of making decisions related to the standards for controlling the quality of design through achieving the concept and comprehensive quality standards for the elements of production and production processes, to achieve rapid leaps in the rates of economic growth of countries .

3- The necessity to expedite the application of the proposed systems to manage the design quality system and the elements of production management and production processes to achieve the concept of total quality.

\section{References}

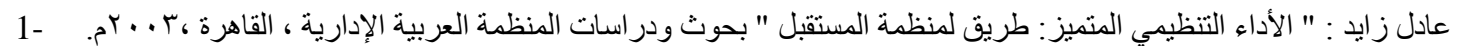

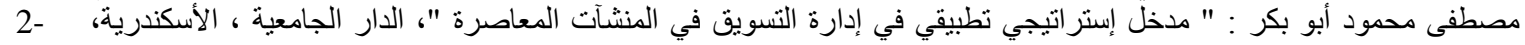

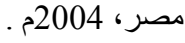

3- Books: 1- Abdu Hassan, H.S, "Total Quality Management", M.s.c. Thesis Barbly University USA, 2006.

4- Arora, S.c, "Applying ISO 9000 Quality management system" Genève: International trade Center, 2014.

5- Barron, F,H, and Barrett, B.E. "Decision Quality using Ranked Attribute weight " management science, Vol 3, 2012.

6- Dilworth, J, B. "Production and operations management" 5th ed., New York, Mc Graw - Hill, (2013).

7- Reid, R. D\& Sanders, N., R" Operations management "John Wiley \& Sons, New York, Inc. (2002).

8- Russell, R.S and Tayler, B.W "Operation management multimedia in Version" third edition, prentice hall, New Jersey, 2000.

9- Stebbing Lione," Quality Assurance: The Rout to Efficiency and Competitiveness "Chichester, ELLIS Harwood limited, 2nd ed., 2012".

Received: February 15, 2018

Accepted: April 20, 2018 